Gut, 1963, 4, 27

\title{
Torsion of the gall bladder
}

\author{
R. K. GREENWOOD
}

From St. Thomas's Hospital, London

EDITORIAL SYNOPSIS Torsion of the gall bladder is an acute abdominal emergency hardly ever diagnosed pre-operatively. This is due largely to a lack of awareness of the existence of the condition, resulting in its rarely being entertained as a possibility in the differential diagnosis. A case is described and presented in relation to aetiology and treatment.

\section{HISTORICAL NOTE}

The first recorded case of this condition is accredited to Wendel, who in 1898 reported a case in a young woman who had a floating gall bladder containing stones which had twisted and perforated, giving a pericholecystic abscess. A number of cases have been reported since then, though rarely with actual perforation of the organ. Short and Paul (1934) presented a comprehensive review of some fifty cases in the literature of this country, as did Leger, Debeyre, and Mazingarbe (1945) in France, and Bean and Symond (1953) in America. In recent years isolated cases have been described in this country by Caldwell (1950), by Bell (1955), and by Christensen (1956). The condition has its maximal incidence in elderly patients, though cases have been recorded in young children by Cuervo and Cuervo (1939), Rawson (1953), and Bogle (1955). An interesting report was that of Recht (1952), who described a case of double gall bladder, one half of which had undergone torsion. Krukenberg (1903) and Fischer (1925) have both described patients with recurrent incomplete torsion of the gall bladder. Krabbel (1920) and Kettner (1930) are reputed to have made the correct pre-operative diagnosis, though the former had been fortunate in seeing a similar case a few weeks previously. According to Christensen only five surgeons have seen more than one case. Musavi and Yeager (1959) in reporting a case in America state that 113 cases have been recorded in the world literature, but Levene (1958), in a splendid review of the subject, puts the figure at about two hundred.

\section{CASE REPORT}

The only case of acute torsion of the gall bladder in the records of St. Thomas's Hospital is that of Mrs. E. S., aged 74 years, who was admitted on 24 June 1960.

She gave no history of jaundice or previous biliary disease, but was an idiopathic epileptic and had sustained a number of fractures as a result of falls during fits. The most recent of these, a fractured neck of the femur, some three months previously had necessitated her admission to hospital for internal fixation and after recovery from this she had been transferred to an old people's home. It was there, on 11 June, that she had a further fit and fall, following which she complained of backache. There was no evidence of skeletal injury to account for the pain, though a radiograph was not taken. The backache persisted until 24 June, when she developed abdominal pain and was transferred back to St. Thomas's Hospital. The pain was constant in the upper abdomen; she had not vomited and she had not had her bowels open for two days.

On examination at that time she was a frail, kyphotic, rather senile old woman with a regular pulse rate of 84 beats per minute, a normal temperature, and blood pressure of $180 / 100 \mathrm{~mm} . \mathrm{Hg}$. Her tongue was moist and slightly furred, and there was some foetor oris. The abdomen was thin, soft and not distended and there was no visible peristalsis. A small, firm, tender, immobile mass was easily palpable in the right upper quadrant of the abdomen. There were no other abnormal physical signs.

Her weight was 7 st. $9 \mathrm{lb}$., haemoglobin $94 \%$, blood urea $32 \mathrm{mg} . \%$, plasma sodium $126 \mathrm{mEq} . / 1$., plasma potassium $5 \mathrm{mEq} . / 1$., and plasma chloride $98 \mathrm{mEq} . / 1$. A straight radiograph of the abdomen (in the erect position) revealed no bowel distention or fluid levels.

An enema saponis was given with a good result and her progress observed overnight. The following day, some 18 hours after admission, the patient was obviously more ill. The pain was severe and she also complained of backache. She had not vomited; she remained apyrexial, though the pulse had risen to 96 beats per minute. Examination of the abdomen revealed generalized tenderness, with right-sided rigidity. The mass was no longer palpable; there was a positive release sign and bowel sounds were absent.

She was thought to be suffering from peritonitis, possibly due to some internal strangulation, and immediate laparotomy was considered advisable. Examination under anaesthetic demonstrated a mass in the right upper quadrant and a right upper paramedian 


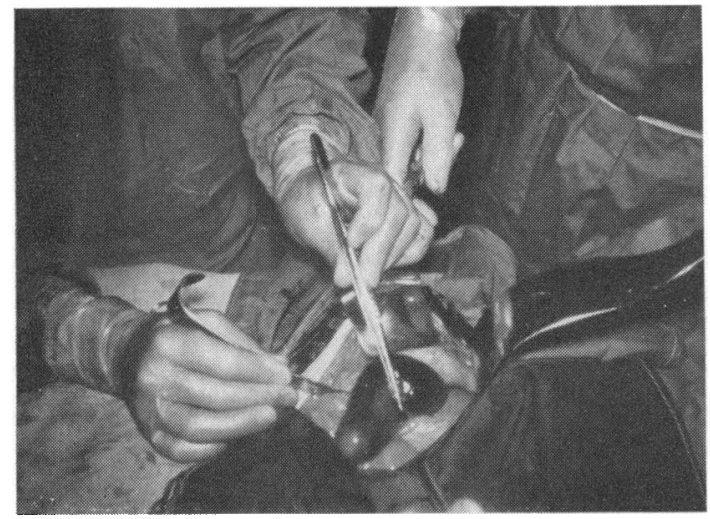

FIG. 1. Operative findings, showing the black, turgid gall bladder. The dissecting forceps are on the twisted pedicle.

incision was carried out. There was a little clear fluid in the peritoneal cavity and the gall bladder was a turgid black mass (Fig. 1). It had a complete peritoneal covering, apart from a 2 in. long mesentery slinging it from the under surface of the liver, and had undergone torsion through $360^{\circ}$ in a clockwise direction. It appeared gangrenous and not far from perforation. The torsion was easily untwisted and the organ was found to be of normal size. The wall was thin and there was no obvious evidence of previous disease. It did not contain any stones. Cholecystectomy was accomplished without difficulty, the wound was closed in layers, and a stab drain inserted. The gall bladder measured $10 \times 5 \times 2.5$ cm. (Fig. 2); it contained blood-stained bile and histologically was found to be totally infarcted.

The patient's condition during operation remained satisfactory and the post-operative progress was without incident, both the abdominal pain and backache disappearing.

\section{DISCUSSION}

For a gall bladder to tort it must either possess a mesentery, preferably with a narrow pedicle, slinging it from the under surface of the liver, or else lie free in the peritoneal cavity, connected with the remainder of the biliary system by the cystic duct only. The normal arrangement is for the organ to lie in a fossa under the liver, clothed only with peritoneum on the inferior surface. However, the fundus frequently projects anterior to the lower edge of the liver with a complete peritoneal covering, and, according to Brewer (1899) and Gross (1936), some $5 \%$ of cases possess a true mesentery, though clinical experience would place the incidence lower than this. A mesentery can be either congenital or else acquired either as a result of liver atrophy, e.g., in cirrhosis, with consequent redundancy of the capsule (Levene, 1958) or disappearance of surrounding tissue as part

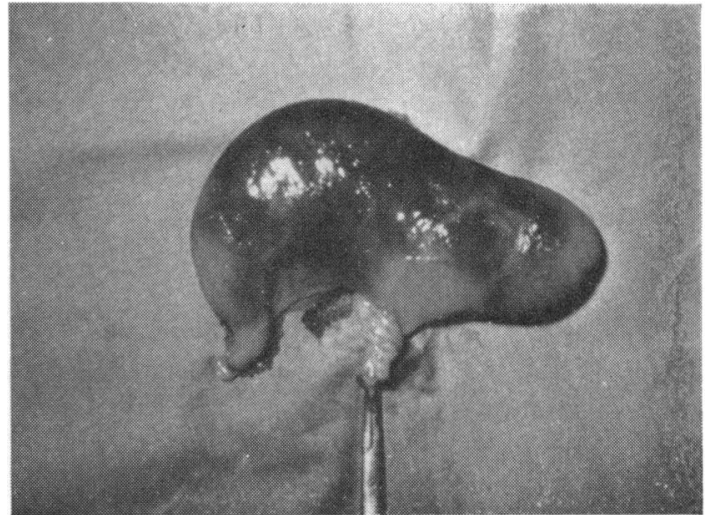

FIG. 2. Gall bladder after removal, showing torsion of the pedicle.

of the general metabolic changes of old age resulting in a floating gall bladder (Gross, 1936; Maingot, 1961). A free-lying gall bladder is congenital and Case (1951) asserts that only this variety can undergo true torsion, the presence of a mesentery reducing any movement to that of axial rotation.

Like all gall bladder disease torsion is more common in females than in males, the figures varying from 5:1 (Short and Paul) to 2:1 (Levene). There is a very definite age relationship, being much commoner in the elderly (Gross, 1953). The maximum incidence is in the 65-75 age group (Maingot, 1961). This late onset favours the mobility of the gall bladder being acquired, most reported cases (including the one here) occurring in rather senile, wasted old women. The cases reported in children, however, are more likely to have had congenitally free gall bladders. The state of the gall bladder before torsion appears to be variable. Wendel's original case had 213 gall stones, and the incidence of either stones or chronic cholecystitis in reported cases is higher than that found in the general population. This is surprising as chronic infection, by causing fibrosis, would be expected to diminish the mobility of the organ, thus rendering torsion less likely. However, many cases of torsion, like the one recorded here, have taken place in a normal gall bladder. Two have been reported in association with myocardial infarct (Marks, Shedd, and Lock, 1954; Levene, 1958).

Assuming that the gall bladder is free to twist why does it do so? The aetiology is unknown. Caldwell postulated that a tortuous arteriosclerotic cystic artery might encourage rotation and Rais and Thulin (1957) that the kyphoscoliosis of old age by altering the position of the abdominal organs might contribute. Most authorities suggest that peristalsis in the 
neighbouring viscera, stomach, duodenum, or transverse colon might initiate a twisting of the gall bladder. The movement of the viscus is presumed to take purchase on one aspect of the organ and the direction of the peristaltic wave in relation to the particular surface of the gall bladder determines the direction of torsion, i.e., clockwise or anticlockwise. Violent movement of the body or sudden falls have also been incriminated (Berry, 1939), and this explanation might well be applicable in the case reported here, a known epileptic who had recently sustained a number of heavy falls. Ten days before the onset of acute torsion, in fact, she had fallen and following this complained of the backache which had persisted right up to the time that the torsion was treated surgically. Levene (1958) has pointed out that the organ itself must be its own twisting agent and that it is more likely to tort if it is heavy. He suggests that increase in weight might be due to a large solitary stone, or to blockage of the cystic duct. However, as already stated, stones are by no means a necessary feature of torsion and there are no recorded cases of twisted mucocoeles-surely the heaviest of gall bladders. There are also no known instances of torsion of a distended gall bladder associated with carcinoma of the head of the pancreas.

The diagnosis of the condition is difficult. Short and Paul (1934) consider it feasible and Krabbel (1920) and Kettner (1930) have made it correctly. The characteristic features are said to be acute pain in the right upper abdomen, perhaps colicky in nature, associated with vomiting and the presence of a sharply demarcated area of localized tenderness, together with a mass which might come and go. In the case reported here, however, there was no vomiting at any time, which would appear to be exceptional. Another interesting feature in this case was the severe backache, which was quite marked, and disappeared immediately after operation. The common preoperative diagnoses are cholecystitis, intestinal obstruction, neoplasm of the colon, perforated peptic ulcer, and appendicitis. It is understandable that when gangrene and shock have supervened the signs of peritonitis will render any mass impalpable. In a late case, therefore, the condition should be considered in the differential diagnosis of peritonitis. It can be seen from the clinical presentation of this case the diagnostic difficulties involved. However, provided that there is no delay in surgery it is doubtful whether a correct pre-operative diagnosis is of anything other than academic value.

The treatment of torsion of the gall bladder is early cholecystectomy and all authorities agree that the operation is particularly easy. The post-operative course is usually smooth and uneventful. Arthur (1937) reported a mortality of $16 \%$. This would appear unreasonably high today, however. Presumably age and delay in surgery, leading to perforation, contributed to this figure. Perforation, however, is rare and provided laparotomy is resorted to without delay there is no reason to expect a mortality higher than that of any operation in that age group.

In conclusion, therefore, torsion of the gall bladder remains a rare, acute abdominal emergency. It is unlikely to be diagnosed correctly pre-operatively without previous experience of a case.

I should like to thank Mr. R. J. Furlong for permission to publish this case, and Mr. Harcourt-Webster for his photographs.

\section{REFERENCES}

Arthur, H. R. (1937). Acute torsion of the gall-bladder. Brit. med. J., 2, 265-266.

Bean, L. L., and Symond. D. A. (1953). Acute torsion of the gallbladder. U.S. armed Forces med. J., 4, 411-413.

Bell, D. M. (1955). Torsion of gall-bladder. Brit. med. J., 1, 29-30.

Berry, W. H. (1939). Torsion of the gallbladder. J. Amer. med. Ass., $112,1580-1581$

Brewer, G. E. (1899). Preliminary report on the surgical anatomy of the gall-bladder and ducts from an analysis of one hundred dissections. Ann. Surg., 29, 721-730.

Bogle, J. H. (1955). Gangrene of the gall bladder due to torsion in a nine-year-old child. Amer. J. Dis. Child., 89, 484-485.

Caldwell, K. P. S. (1950). Torsion of gall bladder. Brit. med. J., 2, 1425.

Case, T. C. (1951). Acute torsion of the gallbladder. Amer. J. Surg., 82, 749-753.

Christensen, E. (1956). Torsion of the gall-bladder. Brit. med. J., 2, 1160.

Cuervo, S., and Cuervo, T. (1939). A propósito de dos casos de vólvulo biliar en niños de cinco y once años de edad respectivamente. Arch. Soc. Estud. clin. Habana, 33, 295-305.

Fischer, A. (1925). Uber torsion der gallenblase. Zbl. Chir., 52, 1527-31.

Gross, R. E. (1936). Congenital anomalies of gallbladder. Review of 148 cases, with report of double gallbladder. Arch. Surg., 32, 131-162.

Gross, R. E. (1953). The Surgery of Infancy and Childhood. Saunders, Philadelphia.

Kettner, G. (1930). Úber einen Fall kompletter Torsion der Gallenblase. Zbl. Chir., 57, 589-590.

Krabbel, M. (1920). Die Stieltorsion der Gallenblase. Dtsch. $Z$. Chir., 154, 76-86.

Krukenberg, H. (1903). Ueber Gallenblasenkoliken ohne Gallensteine. Berl. klin. Wschr., 40, 667-668.

Leger, L., Debeyre, J., and Mazingarbe, A. (1945). Volvulus de la vésicule biliaire. J. Chir. (Paris), 61, 21-36.

Levene, A. (1958). Acute torsion of the gall bladder. Post-mortem findings in two cases. Brit. J. Surg., 45, 338-340.

Maingot, R. H. (1961). Abdominal Operations, 4th eo. Lewis, London.

Marks, R. M., Shedd, C. G., and Locke, A. W. (1954). Volvulus of the gall bladder associated with acute myocardial infarction. Report of a case and review of the literature. New Engl. J. Med., 251, 95-97.

Musavi, S., and Yeager, G. H. (1959). Torsion of the gallbladder. J. Amer. med. Ass., 170, 670-671.

Rawson, H. D. (1953). Torsion of the gall-bladder in a child of twelve with a review of the literature. Aust. N.Z. J. Surg., 22, 315-317.

Recht, W. (1952). Torsion of a double gall-bladder. A report of a case and a review of the literature. Brit. J. Surg., 39, 342-344.

Rais, O., and Thulin, C. A. (1957). Torsion of the gallbladder. Report of one case and review of literature. Acta chir. scand., 113, 289-293.

Short, A. R., and Paul, R. G. (1934). Torsion of the gall-bladder. Brit. J. Surg., 22, 301-309.

Wendel, A. V. (1898). Case of floating gall-bladder and kidney complicated by cholelithiasis with perforation of the gallbladder. Ann. Surg., 27, 199-202. 